\title{
28 Research Square \\ Long-term Outcomes of Stereotactic Radiosurgery for Skull Base Tumors Involving the Cavernous Sinus
}

\section{Motoyuki Umekawa}

University of Tokyo Hospital: Tokyo Daigaku Igakubu Fuzoku Byoin

YUKI SHINYA ( $\square$ yukishinya6155@gmail.com)

University of Tokyo Hospital: Tokyo Daigaku Igakubu Fuzoku Byoin https://orcid.org/0000-0003-0097-5804

Hirotaka Hasegawa

University of Tokyo Hospital: Tokyo Daigaku Igakubu Fuzoku Byoin

Masahiro Shin

University of Tokyo Hospital: Tokyo Daigaku Igakubu Fuzoku Byoin

Mariko Kawashima

University of Tokyo Hospital: Tokyo Daigaku Igakubu Fuzoku Byoin

Atsuto Katano

University of Tokyo Hospital: Tokyo Daigaku Igakubu Fuzoku Byoin

Nobuhito Saito

University of Tokyo Hospital: Tokyo Daigaku Igakubu Fuzoku Byoin

\section{Research Article}

Keywords: cavernous sinus, skull base tumors, stereotactic radiosurgery, gamma knife radiosurgery

Posted Date: October 20th, 2021

DOl: https://doi.org/10.21203/rs.3.rs-986293/v1

License: (c) (i) This work is licensed under a Creative Commons Attribution 4.0 International License. Read Full License

Version of Record: A version of this preprint was published at Journal of Neuro-Oncology on January 14th, 2022. See the published version at https://doi.org/10.1007/s11060-021-03921-5. 


\section{Abstract}

Purpose

Stereotactic radiosurgery (SRS) is an effective and less invasive therapeutic option for cavernous sinus (CS) tumors. However, its long-term effectiveness and neurological outcomes have yet to be fully elucidated. We aimed to examine the long-term outcomes of SRS for CS tumors.

\section{Methods}

Overall, 127 patients with benign CS tumors, including 91 with meningioma, 14 with trigeminal schwannoma (TS), 14 with non-functioning pituitary adenoma (PA), and eight with cavernous hemangioma $(\mathrm{CH})$, treated with SRS at our institution from 1990 to 2018, were included. Tumor control and functional preservation/recovery were evaluated in detail.

Results

The mean post-SRS follow-up period was 102 months. The progression-free survivals (PFSs) were $97 \%$ at 5 years, $90 \%$ at 10 years, and $88 \%$ at 15 years for the entire cohort; $96 \%$ at 5 years and $87 \%$ at 10 years for meningiomas; and $100 \%$ at 10 years for the other tumors. No significant difference was observed among the tumor types (log-rank test; meningioma vs. TS, $p=0.232$, meningioma vs. PA, $p=0.297$, meningioma vs. $\mathrm{CH}, p=0.277)$. Improvement in cranial nerve (CN) function was observed in $35(27 \%)$ patients. TSs tended to show CN improvements more often than meningiomas did (total improvements, $62 \%$ vs. $23 \% ; p=0.004$, eye movement function, $100 \%$ vs. $20 \% ; p=0.002$ ). Deterioration, or development of new CN deficits, was observed in 11 (9\%) patients.

\section{Conclusion}

SRS provides durable tumor control and contributes to sufficient preservation of $\mathrm{CN}$ function.

\section{Introduction}

The cavernous sinus (CS) is an important anatomical structure containing the internal carotid artery (ICA), and the third, fourth, fifth, and sixth cranial nerves (CNs). A variety of benign tumors, such as meningiomas, trigeminal schwannomas (TS), pituitary adenomas (PA), and cavernous hemangiomas $(\mathrm{CH})$, can arise in or extend into this structure, causing impairment of visual function, extraocular movement, facial sensory function, and other CN functions [1-4]. Surgical resection is the standard primary treatment to achieve immediate mass reduction and obtain a histopathological diagnosis. Despite well-established microscopic and endoscopic skull base techniques, surgical interventions for such tumors remain challenging due to their deep skull base location and proximity to the ICA, CNs, visual pathways, and pituitary gland. Preservation of $\mathrm{CN}$ may require surgeons to leave tumor remnants behind, and tumor recurrence/regrowth is possible [5-7]. Radiotherapy plays an important role in balancing tumor control and functional preservation, but whether functional recovery is achievable following radiotherapy remains questionable, especially in cases of large symptomatic tumors, since immediate mass reduction is not achievable [6].

Stereotactic radiosurgery (SRS) is a less invasive treatment option utilizing head fixation and highly focused narrow beam radiation that enables precise targeting with a steep dose fall-off. Given the structural features of the CS in which the CNs run along its outer wall, it is theoretically feasible to intensely irradiate tumors while minimizing irradiation to the CNs. Previous literature has reported favorable short- to mid-term outcomes, following either SRS alone or in combination with surgery [8-11]. CS-specific radiation-induced adverse events (RAE), deterioration of CN III-VI function, and ICA stenosis/occlusion, albeit rare, have been reported [12-18]. However, there remains a paucity of data on its long-term outcomes. 
This study aimed to clarify the long-term outcomes of tumor control and CN functioning following SRS for benign CS tumors.

\section{Methods}

\section{Patient and tumor characteristics}

The data of 190 patients with CS tumors, treated with SRS from June 1990 to June 2018 at our institution, were collected from the institutional gamma knife database. Both intra-CS tumors and para-CS tumors extending into the CS were defined as CS tumors. The exclusion criteria were: (1) functioning PAs that required extraordinal high dose irradiation (25 Gy or higher) ( $n=22)$, (2) pathologically confirmed non-benign tumors, including World Health Organization (WHO) grade II/III meningiomas $(n=12)$, hemangiopericytomas $(n=1)$, chordomas $(n=18)$, chondrosarcomas $(n=9)$, and metastatic tumors $(n=1)$. As a result, data on 127 patients with benign CS tumors, including 91 meningiomas, 14 TSs, 14 nonfunctioning PAs, and $8 \mathrm{CHs}$, were included in the analysis.

Most diagnoses were based on histopathological findings from prior surgery $(n=89)$. The timing of SRS for postoperative recurrent $(n=45)$ or residual tumor $(n=44)$ was determined using the judgment of the surgeon or referring physician or by patient request, without any arbitrary selection. Radiographic diagnosis, without prior surgery, was used in 38 cases (19 meningiomas, 12 TSs, and $7 \mathrm{CHs}$ ). All radiographic images were reviewed by two independent neuroradiologists and attending neurosurgeons. The study was approved by the Institutional Review Board of our institution (\#2231) and conducted in compliance with the principles of the Declaration of Helsinki and the Strengthening the Reporting of Observational Studies in Epidemiology (STROBE) guidelines. All patients provided written informed consent for study participation.

\section{The procedures and techniques of SRS}

Leksell Gamma Knife (Elekta Instruments, Stockholm, Sweden) was used for all SRS treatments. The detailed treatment process is reported in a previous paper $[19,20]$. After head fixation using a Leksell frame (Elekta Instruments, Stockholm, Sweden), stereotactic imaging (CT before July 1996, MRI between August 1996 and January 2018, followed by conebeam CT) was performed to obtain precise tumor data. Neurosurgeons and radiation oncologists performed radiosurgical planning using commercially available software (KULA planning system) until 1998 and Leksell Gamma Plan thereafter [Elekta Instruments]). In principle, 14-16 Gy was prescribed to the tumor margin using a $50 \pm 5 \%$ isodose line. If the tumor was suspected to be aggressive and was sufficiently distant from radiosensitive cerebral structures, such as the optic apparatus or the brainstem, the tumor margin dose was increased to $16 \mathrm{~Gy}$ to achieve long-term tumor control.

\section{Follow-up and treatment outcomes}

After SRS, MRI was regularly performed every six months for the first couple of years and annually thereafter. Radiographic findings were independently assessed by neuroradiologists and neurosurgeons. Transient expansion, typically occurring in schwannomas due to radiation-induced tumor swelling at around six months after SRS, followed by shrinkage at approximately 18 months, was meticulously distinguished from actual tumor progression by evaluating consecutive MRIs [21, 22]. The neurological status of the patients and their responses to treatment were prospectively collected at each hospital visit, and a Common Terminology Criteria for Adverse Events (CTCAE, version 5.0) grade was retrospectively assigned on the basis of the descriptions. Data on patients who dropped out of regular follow-ups or returned to referring physicians were collected via telephone conversation, and follow-up radiographic images were obtained for our independent review.

\section{Statistical methods}


Baseline characteristics of the patients were compared using the chi-square test for categorical variables and the MannWhitney $U$ test for continuous variables. Progression-free survival (PFS) rates were calculated using the Kaplan-Meier method and compared among tumor types using the log-rank test. A tumor was considered "progression-free" if there was no > 2-mm increase in tumor diameter in any direction on two or more consecutive post-SRS imaging studies. Factors associated with PFS were examined using bivariate and multivariable Cox proportional hazard analyses. Continuous variables were entered into models after being dichotomized using their median values. Where post-SRS recurrence/regrowth was confirmed, recurrence patterns and features were examined in more detail. Post-SRS CN outcomes were summarized, and factors associated with functional improvement, deterioration, and new deficits were examined with logistic regression analysis, and these rates were calculated and compared using the Kaplan-Meier method. Statistical analyses were performed using JMP Pro 15 software (SAS Institute Inc., Cary, NC, USA).

\section{Results}

\section{Participant characteristics}

Patient characteristics are shown in Table 1. The mean post-SRS follow-up period was 102 months $( \pm$ standard deviation [SD] of 79 months). When comparing the baseline characteristics between tumor types, the maximum diameter (30 mm vs. $24 \mathrm{~mm} ; p=0.029)$ was significantly larger, and the prescription dose (15.9 vs. $14.6 \mathrm{~Gy} ; p=0.012)$ and central dose (33.4 vs. $30.7 \mathrm{~Gy} ; p=0.039$ ) were significantly higher in meningiomas than in TS. Patients underwent prior surgery significantly more often in the meningioma group than the TS and $\mathrm{CH}$ groups (meningioma 79\%, TS 14\% [ $p=0.001]$, and $\mathrm{CH} \mathrm{13 \%} \mathrm{[} p=0.001])$. Of those, 21 patients with meningioma (23\%), and three patients with PA (21\%) had had surgery two or more times before SRS. 
Table 1

Baseline characteristics of the patients

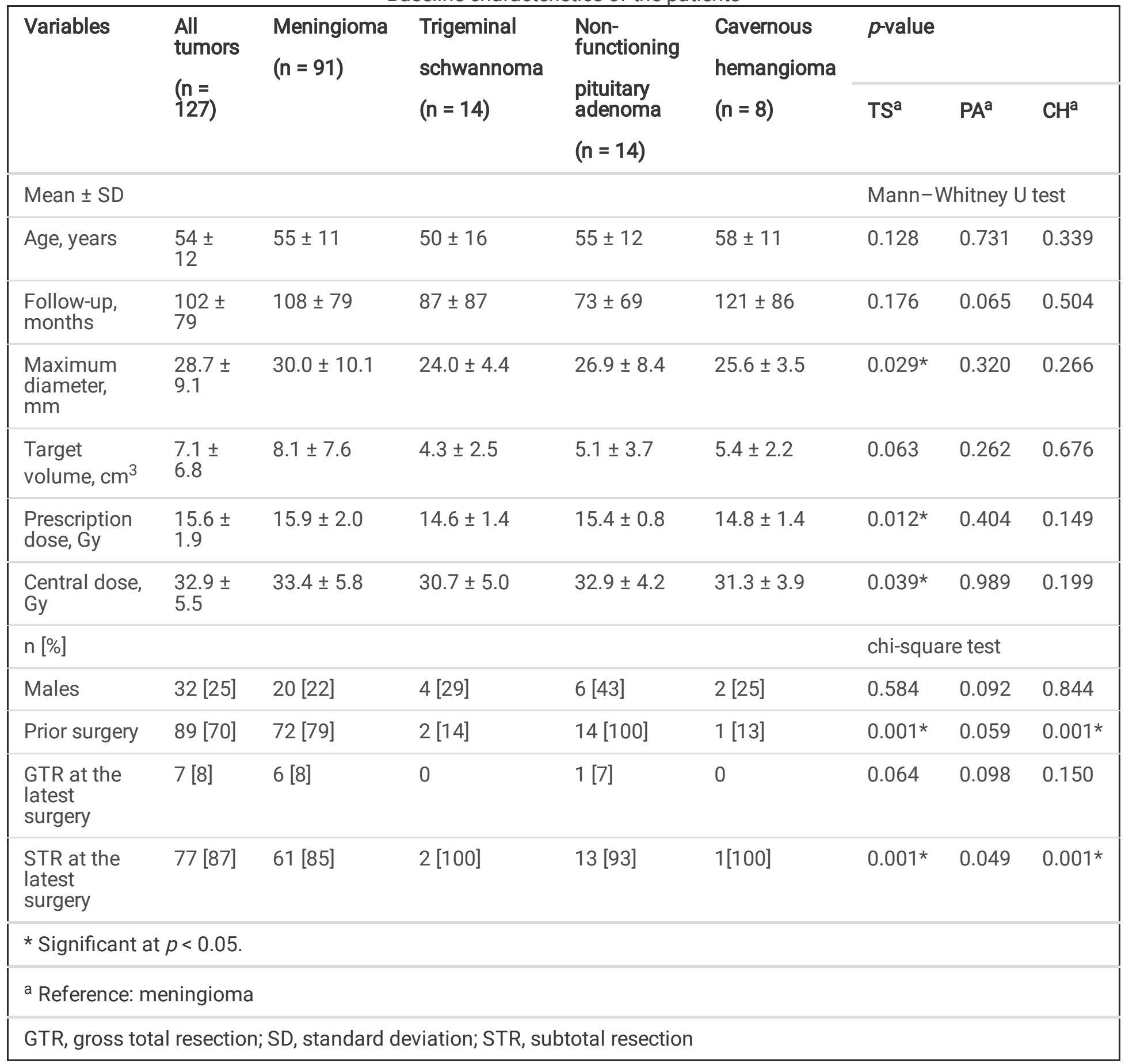

\section{Tumor control}

Of all the patients, 126 (99\%) were alive at the final follow-up visit, and the single death was due to suicide, unrelated to the tumor and associated treatment. At the last follow-up, 56 (44\%) tumors had decreased in size, 61 (48\%) remained unchanged, and 10 (8\%) increased in size. Tumor shrinkage was observed in 32 patients (35\%) with meningioma, 10 (71\%) with TS, seven (50\%) with PA, and seven (81\%) with $\mathrm{CH}$. Tumor progression was not observed except for ten patients with meningioma. In the entire cohort, the PFS was $97 \%$ at 5 years, $90 \%$ at 10 years, and $88 \%$ at 15 years (Figure $1 \mathrm{~A})$. The tumor specific PFS was $96 \%$ at 5 years, $87 \%$ at 10 years for meningioma, and $100 \%$ at 10 years for the other tumors. There were no significant differences among tumor types in PFS ((log-rank test; meningioma vs. TS, $p=0.232$; meningioma vs. PA, $p=0.297$; meningioma vs. $\mathrm{CH}, p=0.277$; Figure $1 \mathrm{~B}$ ). PFS was $100 \%$ at 5 years and $94 \%$ at 10 years with SRS alone; $96 \%$ at 5 years and $89 \%$ at 10 years for SRS with prior surgery (log-rank test; $p=0.082$, Figure 1C). 
Since tumor recurrence was observed only in meningiomas, the analysis of potential risk factors for tumor recurrence were performed in meningiomas. No significant factors were found in the bivariate and multivariable analyses (Online Resource Supplementary Table 1). Patients with post-SRS recurrence are summarized in Online Resource Supplementary Table 2. All recurrences occurred in meningiomas, a median of 87 months (range, 14-208 months) after SRS. Nine (90\%) tumors were post-surgical recurrence, and three (30\%) tumors were treated with suboptimal radiation coverage because of proximity to the optic apparatus or brainstem structure. The patterns of recurrence were intra-field in four (40\%) patients and marginal (recurrence occurred out of the radiation field but within $20 \%$ isodose line) in six (60\%). PFS in meningioma was $100 \%$ at 5 years and $89 \%$ at 10 years for SRS alone; $95 \%$ at 5 years and $87 \%$ at 10 years for SRS with prior surgery (log-rank test; $p=0.207$, Figure 1D).

\section{Improvement of cranial nerve deficits}

The details of CN function are summarized in Table 2. Eighty-seven patients (69\%) had $132 \mathrm{CN}$ deficits before SRS. The rate of pre-SRS CN deficits was the highest in meningiomas (69/91, 76\%), followed by 12 (86\%) in TSs, four (29\%) in PAs, and two (25\%) in $\mathrm{CHs}$. 
Table 2

Improvement and deterioration of cranial nerve function after radiosurgery, stratified by tumor type

\begin{tabular}{|c|c|c|c|c|c|c|c|c|}
\hline \multicolumn{9}{|c|}{ Improvement in cranial nerve function } \\
\hline \multirow[t]{2}{*}{ Variables } & \multirow{2}{*}{$\begin{array}{l}\text { All } \\
\text { tumors } \\
(n= \\
87)\end{array}$} & \multirow{2}{*}{$\begin{array}{l}\text { Meningioma } \\
(\mathrm{n}=69)\end{array}$} & \multirow{2}{*}{$\begin{array}{l}\text { Trigeminal } \\
\text { schwannoma } \\
(\mathrm{n}=12)\end{array}$} & \multirow{2}{*}{$\begin{array}{l}\text { Non- } \\
\text { functioning } \\
\text { pituitary } \\
\text { adenoma } \\
(n=4)\end{array}$} & \multirow{2}{*}{$\begin{array}{l}\text { Cavernous } \\
\text { hemangioma } \\
(n=2)\end{array}$} & \multicolumn{3}{|l|}{$p$-value } \\
\hline & & & & & & $\mathrm{TS}^{\mathrm{a}}$ & $\mathrm{PA}^{\mathrm{a}}$ & $\mathrm{CH}^{\mathrm{a}}$ \\
\hline $\begin{array}{l}\text { Pre-SRS total } \\
\text { deficits, }(n)\end{array}$ & 132 & 111 & 13 & 4 & 4 & & & \\
\hline II, n (\%) & $4(16)$ & $4(20)$ & $\rho^{+}$ & $0(0)$ & $0(0)$ & $\mathrm{N} / \mathrm{A}$ & 0.394 & 0.484 \\
\hline $\begin{array}{l}\text { EOM (III, IV, VI), } \\
\text { n (\%) }\end{array}$ & $\begin{array}{l}11 \\
(24)\end{array}$ & $8(20)$ & $3(100)$ & $0(0)$ & $0(0)$ & $0.002^{\star}$ & 0.624 & 0.624 \\
\hline V, n (\%) & $\begin{array}{l}16 \\
(36)\end{array}$ & $11(31)$ & $5(50)$ & $\mu^{+}$ & $\mu^{+}$ & 0.279 & N/A & N/A \\
\hline Ptosis, n (\%) & $1(50)$ & $0(0)$ & $\mu^{+}$ & $\mu^{+}$ & $1(100)$ & N/A & N/A & 0.157 \\
\hline VII, n (\%) & $2(33)$ & $2(33)$ & $\mu^{+}$ & $\mu^{+}$ & $\mu^{\dagger}$ & N/A & $\mathrm{N} / \mathrm{A}$ & $\mathrm{N} / \mathrm{A}$ \\
\hline VIII, n (\%) & $1(17)$ & $1(17)$ & $\rho^{+}$ & $\rho^{+}$ & $\mu^{+}$ & N/A & N/A & N/A \\
\hline IX, X, n (\%) & $0(0)$ & $0(0)$ & $\rho^{+}$ & $\rho^{+}$ & $\rho^{+}$ & $\mathrm{N} / \mathrm{A}$ & N/A & N/A \\
\hline $\begin{array}{l}\text { Total } \\
\text { improvements, } \\
\text { n (\%) }\end{array}$ & $\begin{array}{l}35 \\
(27)\end{array}$ & $26(23)$ & $8(62)$ & $0(0)$ & $1(25)$ & $0.004^{\star}$ & 0.271 & 0.942 \\
\hline \multicolumn{9}{|c|}{ Deterioration of cranial nerve function } \\
\hline Variables & $\begin{array}{l}\text { All } \\
\text { tumors }\end{array}$ & $\begin{array}{l}\text { Meningioma } \\
(\mathrm{n}=91)\end{array}$ & $\begin{array}{l}\text { Trigeminal } \\
\text { schwannoma }\end{array}$ & $\begin{array}{l}\text { Non- } \\
\text { functioning }\end{array}$ & $\begin{array}{l}\text { Cavernous } \\
\text { hemangioma }\end{array}$ & $p$-value & & \\
\hline & $\begin{array}{l}(\mathrm{n}= \\
127)\end{array}$ & & $(n=14)$ & $\begin{array}{l}\text { pitultary } \\
\text { adenoma }\end{array}$ & $(n=8)$ & $\mathrm{TS}^{\mathrm{a}}$ & $\mathrm{PA}^{\mathrm{a}}$ & $\mathrm{CH}^{\mathrm{a}}$ \\
\hline & & & & $(n=14)$ & & & & \\
\hline II, n (\%) & $1(1)$ & $1(1)$ & $0(0)$ & $0(0)$ & $0(0)$ & 0.694 & 0.694 & 0.766 \\
\hline $\begin{array}{l}\text { EOM (III, IV, VI), } \\
\text { n (\%) }\end{array}$ & $4(3)$ & $4(4)$ & $0(0)$ & $0(0)$ & $0(0)$ & 0.424 & 0.424 & 0.545 \\
\hline $\mathrm{V}, \mathrm{n}(\%)$ & $6(5)$ & $5(5)$ & $1(7)$ & $0(0)$ & $0(0)$ & 0.805 & 0.369 & 0.496 \\
\hline
\end{tabular}

Overall post-SRS improvement of any CN function was observed in 27 of 87 patients (31\%).

* Significant at $p<0.05$

${ }^{\dagger}$ no symptomatic patients in this group

a vs. meningioma

$\mathrm{CH}$, cavernous hemangioma; $\mathrm{CN}$, cranial nerve; $\mathrm{EOM}$, extraocular movement; $\mathrm{PA}$, non-functioning pituitary adenoma; SRS, stereotactic radiosurgery; TS, trigeminal schwannoma

$\mathrm{N} / \mathrm{A}$, no improvement in the relevant cranial nerve function. 


\begin{tabular}{|c|c|c|c|c|c|c|c|c|}
\hline \multicolumn{9}{|c|}{ Improvement in cranial nerve function } \\
\hline $\begin{array}{l}\text { Others (ptosis, } \\
\text { VII, VIII, IX, X), } \\
\text { n (\%) }\end{array}$ & $0(0)$ & $0(0)$ & $0(0)$ & $0(0)$ & $0(0)$ & N/A & N/A & N/A \\
\hline $\begin{array}{l}\text { CTCAE grade } \\
\geq 3, \mathrm{n}(\%)\end{array}$ & $0(0)$ & $0(0)$ & $0(0)$ & $0(0)$ & $0(0)$ & N/A & N/A & N/A \\
\hline Total deficits & $11(9)$ & $10(11)$ & $1(7)$ & $0(0)$ & $0(0)$ & 0.662 & 0.192 & 0.323 \\
\hline \multicolumn{9}{|c|}{ Overall post-SRS improvement of any CN function was observed in 27 of 87 patients (31\%). } \\
\hline \multicolumn{9}{|c|}{ * Significant at $p<0.05$} \\
\hline \multicolumn{9}{|c|}{${ }^{\dagger}$ no symptomatic patients in this group } \\
\hline \multicolumn{9}{|c|}{ a vs. meningioma } \\
\hline \multicolumn{9}{|c|}{$\begin{array}{l}\mathrm{CH} \text {, cavernous hemangioma; } \mathrm{CN} \text {, cranial nerve; EOM, extraocular movement; PA, non-functioning pituitary adenoma; } \\
\text { SRS, stereotactic radiosurgery; TS, trigeminal schwannoma }\end{array}$} \\
\hline
\end{tabular}

In the entire cohort, CN improvement was observed in 35 (27\%) deficits, including four (16\%) visual deficits, 11 (24\%) third, fourth, and sixth CN deficits, 16 (36\%) trigeminal neuropathy and one (50\%) ptosis. Among tumor types, improvement of third, fourth, and sixth CN deficits was significantly more common in patients with TS $(100 \%)$ than in meningioma $(20 \%, p$ $=0.002$ ), whereas no significant difference was observed in improvements in the other $\mathrm{CN}$ deficits. The cumulative rates of post-SRS improvement of CN functions are shown in Figure 2A. The post-SRS CN improvement was observed at a mean \pm SD of $17 \pm 14$ months. More significant improvements were observed in TSs than in meningiomas (log-rank test; $p$ $=0.001$, Figure $2 \mathrm{~B})$. The improvement rates of CN V (57\% vs. $26 \% ; p=0.025)$ and all CN $(41 \%$ vs. $21 \% ; p=0.025)$ were significantly higher in SRS alone than in SRS with prior surgery (Online Resource Supplementary Table 3). Additionally, $105 \mathrm{CN}$ deficits caused by tumor compression were relieved in 32 patients (30\%) after SRS.

\section{Radiation-induced adverse events}

Details of new or worsened CN deficits following SRS are shown in Table 2. Eleven (9\%) CN deficits had deteriorated or newly developed at a mean period of $19 \pm 28$ months following SRS, including one (1\%) visual deficit, four (3\%) extraocular movement disorders, and six (5\%) trigeminal neuropathies. All were mild or transient (CTCAE grade 1-2). The cumulative rates of post-SRS deteriorated/newly developed $\mathrm{CN}$ functions are shown in Figure 2C. There were no significant differences among tumor types (Figure 2D). Aside from the $\mathrm{CN}$ deficits, hydrocephalus was observed in one patient $(0.8 \%)$ with well-controlled meningioma who underwent ventriculoperitoneal shunting 100 months after SRS. In this case, the association between the tumor and hydrocephalus was unclear. No temporal lobe necrosis was observed in the entire cohort. Post-SRS signal change, as a high-intensity signal change on T2-weighted imaging in the temporal lobe, was identified in two patients with meningioma (1.6\%) 3-6 months after SRS; both were asymptomatic and diminished at 13-24 months. Hypopituitarism was observed in one patient $(0.8 \%)$ with meningioma 47 months after SRS, and asymptomatic ICA stenosis was observed in one patient (0.8\%) with meningioma 169 months after SRS.

\section{Discussion}

In this study, we analyzed long-term outcomes of SRS for CS tumors. Using a similar radiosurgical strategy, we defined the tumor margins and prescribed conformally and selectively a marginal dose of 14-16 Gy; the 10-year PFS was $90 \%$, with the post-SRS CN improvement rate reaching $27 \%$, while maintaining a low $\mathrm{CN}$ deterioration rate (9\%). These results 
suggest that SRS would be a reasonable treatment option, providing long-term tumor control with favorable neurological outcomes.

The results showed that the tumor control rate is excellent, especially in non-meningioma CS tumors. Most baseline characteristics of tumors in this cohort were similar, with differences in tumor size and the history of prior surgery. The differences in PFSs between meningioma and non-meningioma tumors possibly reflected differences in tumor biology, which might be due to selection bias in that most meningiomas are postoperative cases. In the literature, tumor control rates were reported to be $77-100 \%$ in TS at median observation periods of $27-91$ months, $89-100 \%$ in non-functioning PA at 36-67 months, and $100 \%$ in $\mathrm{CH}$ at 30-40 months [13-18, 23-28]. Our data are comparable to these studies.

The post-SRS CN improvements were also excellent, likely the result of the high tumor shrinkage rate. Regarding RAEs, our study demonstrated excellent functional preservation rates, which might be due to the highly selective high dose irradiation which SRS can provide. Therefore, non-meningioma CS tumors are an excellent indication for SRS.

Treatment strategies need to be formulated according to the characteristics of individual tumors. PA tumors often have a preexisting effect on the optic nerve, and surgical decompression should often be prioritized. SRS plays an adjunctive role for recurrent/residual tumors and can be a primary treatment modality in TS and $\mathrm{CH}$.

The PFS of meningioma was slightly lower than that of non-meningiomas but was still satisfactory at $96 \%$ at 5 years and $87 \%$ at 10 years. Most previous retrospective studies and the International Stereotactic Radiosurgery Society Practice Guidelines reported excellent tumor control rates of $86-99 \%$ at 5 years and $69-97 \%$ at 10 years with favorable functional preservation rates of $80-100 \%$, consistent with our results $[19,29-40]$. We found that six $(60 \%)$ recurrent meningiomas presented with marginal recurrences after a mid-to-long period of tumor control (range, 67-208 months). Recurrences can be explained by the intrinsic features of meningiomas. They easily blend in the meninges, making it challenging to accurately define tumor margins. It is important to meticulously pursue dural tails using thin-slice MRIs. In post-surgical recurrence/regrowth cases, surgical scar tissue might obscure the true tumor margins. Nine (90\%) recurrences were postoperative cases, and in situ comparisons to pre-operative images may highlight the true extent of the tumor. Although the role of surgery remains debatable, and immediate mass reduction may be necessary in certain cases, primary SRS may be reasonable for selective cases with small- to medium-sized CS tumors, unless the tumor has atypical radiographic features. Four (40\%) cases had in-field recurrence, and three were likely explained by suboptimal coverage because of the proximity of the optic chiasm and brainstem or incomplete coverage of a tumor part extending into the tentorial edge. The remaining case had a WHO grade I tumor with biologically aggressive features, including a Ki-67 index of $15 \%$.

CN dysfunction as post-SRS RAEs has occurred in $1-23 \%$ of patients in the past [8-10, 14-19, 23, 24, 26, 27, 30-34, 3742]. In our study, 11 of all 127 patients (9\%) experienced deterioration or emergence of new CN dysfunction after SRS, which was lower than previously reported (Online Resource Supplementary Table 4). Notably, 10 of 11 (91\%) of these occurred in patients with CS-meningioma. There was no significant difference among tumor types, and all of the dysfunctions were either CTCAE grade 1 or 2. Comparing surgery and SRS, a meta-analysis of 2065 CS-meningiomas showed that the incidence of neurological complications was significantly lower with SRS alone (25.7\%) compared with SRS after surgery (59.6\%) [43]. We failed to find a similar pattern, which could be explained by our relatively small patient number, although it might be due to our lower RAE rate. A certain portion of RAEs may be avoidable by meticulously defining tumor margins and reducing direct irradiation to the CNs using thin-slice MRIs. Based on these results, SRS would be a safe modality for preserving CN function in CS tumors. Aside from CN deficits, we also identified one carotid artery stenosis $(0.8 \%)$. In previous reports on SRS for PA and CH, the incidence of radiation-induced ICA stenosis/occlusion range was $0.4-2.8 \%[44,45]$. Although ICA stenosis/occlusion is rare and rarely becomes symptomatic, long-term followup is needed. 
This study has several limitations. First, it was a retrospective, single-institution study with potential selection bias. In addition, the clinical practice standards specific to the institution were used, thereby impairing the generalizability of the findings. Second, 38 tumors in this cohort were radiographically diagnosed, therefore the certainty of the diagnoses could be less reliable than those with histological confirmation. Finally, a larger sample size for each tumor type would be desirable for future studies to confirm our findings.

\section{Conclusion}

We confirmed that SRS achieved excellent treatment efficacy for benign skull base tumors invading the CS. It could achieve long-term tumor control and enable sufficient preservation of $\mathrm{CN}$ function.

\section{Declarations}

- Funding: This work was supported by JSPS KAKENHI (grant number 19K24042 to Yuki Shinya).

- Conflicts of interest: The authors have no conflicts of interest to declare that are relevant to the content of this article.

- Ethics approval: The study was approved by the Institutional Review Board of our institution (\#2231) and performed in accordance with the ethical standards as laid down in the 1964 Declaration of Helsinki and its later amendments or comparable ethical standards.

- Informed consent: All patients provided written informed consent for study participation.

- Data availability: The datasets generated during and/or analysed during the current study are available from the corresponding author on reasonable request.

- Author contributions: Conceptualization: Motoyuki Umekawa, Yuki Shinya; Methodology: Motoyuki Umekawa, Yuki Shinya; Formal analysis and investigation: Motoyuki Umekawa, Yuki Shinya; Writing - original draft preparation: Motoyuki Umekawa; Writing - review and editing: Yuki Shinya, Hirotaka Hasegawa, Masahiro Shin, Mariko Kawashima, Atsuto Katano, and Nobuhito Saito.; Funding acquisition: Yuki Shinya; Resources: Yuki Shinya, Hirotaka Hasegawa, Shin Masahiro, Mariko Kawashima, Atsuto Katano; Supervision: Masahiro Shin and Nobuhito Saito.

\section{References}

1. Adegbite AB, Khan MI, Paine KW, Tan LK (1983) The recurrence of intracranial meningiomas after surgical treatment. J Neurosurg 58: 51-56 doi:10.3171/jns.1983.58.1.0051

2. McCormick PC, Bello JA, Post KD (1988) Trigeminal schwannoma. Surgical series of 14 cases with review of the literature. J Neurosurg 69: 850-860 doi:10.3171/jns.1988.69.6.0850

3. Zada G, Kelly DF, Cohan P, Wang C, Swerdloff R (2003) Endonasal transsphenoidal approach for pituitary adenomas and other sellar lesions: an assessment of efficacy, safety, and patient impressions. J Neurosurg 98: 350-358 doi:10.3171/jns.2003.98.2.0350

4. Tagle P, Huete I, Méndez J, del Villar S (1986) Intracranial cavernous angioma: presentation and management. J Neurosurg 64: 720-723 doi:10.3171/jns.1986.64.5.0720

5. Rennert RC, Ravina K, Strickland BA, Bakhsheshian J, Fredrickson VL, Russin JJ (2018) Complete cavernous sinus resection: an analysis of complications. World Neurosurg 119: 89-96 doi:10.1016/j.wneu.2018.07.206

6. Nanda A, Thakur JD, Sonig A, Missios S (2016) Microsurgical resectability, outcomes, and tumor control in meningiomas occupying the cavernous sinus. J Neurosurg 125: 378-392 doi:10.3171/2015.3.JNS142494 
7. O'Sullivan MG, van Loveren HR, Tew JM, Jr. (1997) The surgical resectability of meningiomas of the cavernous sinus. Neurosurgery 40: 238-244; discussion 245-237

8. Tishler RB, Loeffler JS, Lunsford LD, Duma C, Alexander E, 3rd, Kooy HM, Flickinger JC (1993) Tolerance of cranial nerves of the cavernous sinus to radiosurgery. Int J Radiat Oncol Biol Phys 27: 215-221 doi:10.1016/03603016(93)90230-s

9. Leber KA, Bergloff J, Pendl G (1998) Dose-response tolerance of the visual pathways and cranial nerves of the cavernous sinus to stereotactic radiosurgery. J Neurosurg 88: 43-50 doi:10.3171/jns.1998.88.1.0043

10. Liu AL, Wang C, Sun S, Wang M, Liu P (2005) Gamma knife radiosurgery for tumors involving the cavernous sinus. Stereotact Funct Neurosurg 83: 45-51 doi:10.1159/000085544

11. Tripathi M, Batish A, Kumar N, Ahuja CK, Oinam AS, Kaur R, Narayanan R, Gurnaani J, Kaur A (2020) Safety and efficacy of single-fraction gamma knife radiosurgery for benign confined cavernous sinus tumors: our experience and literature review. Neurosurg Rev 43: 27-40 doi:10.1007/s10143-018-0975-8

12. Starke RM, Williams BJ, Hiles C, Nguyen JH, Elsharkawy MY, Sheehan JP (2012) Gamma knife surgery for skull base meningiomas. J Neurosurg 116: 588-597 doi:10.3171/2011.11.JNS11530

13. Huang CF, Kondziolka D, Flickinger JC, Lunsford LD (1999) Stereotactic radiosurgery for trigeminal schwannomas. Neurosurgery 45: 11-16; discussion 16 doi:10.1097/00006123-199907000-00002

14. Sheehan J, Yen CP, Arkha Y, Schlesinger D, Steiner L (2007) Gamma Knife surgery for trigeminal schwannoma. Journal of Neurosurgery 106: 839-845 doi:DOI 10.3171/jns.2007.106.5.839

15. Sun J, Zhang J, Yu X, Qi S, Du Y, Ni W, Hu Y, Tian Z (2013) Stereotactic radiosurgery for trigeminal schwannoma: a clinical retrospective study in 52 cases. Stereotact Funct Neurosurg 91: 236-242 doi:10.1159/000345258

16. Ryu J, Lee SH, Choi SK, Lim YJ (2018) Gamma knife radiosurgery for trigeminal schwannoma: a 20-year experience with long-term treatment outcome. J Neurooncol 140: 89-97 doi:10.1007/s11060-018-2934-1

17. Snyder MH, Shepard MJ, Chen CJ, Sheehan JP (2018) Stereotactic radiosurgery for trigeminal schwannomas: A 28-year single-center experience and review of the literature. World Neurosurg 119: e874-e881 doi:10.1016/j.wneu.2018.07.289

18. Pomeraniec IJ, Taylor DG, Cohen-Inbar O, Xu Z, Lee Vance M, Sheehan JP (2019) Radiation dose to neuroanatomical structures of pituitary adenomas and the effect of gamma knife radiosurgery on pituitary function. $J$ Neurosurg 132: 1499-1506 doi:10.3171/2019.1.JNS182296

19. Shin M, Kurita H, Sasaki T, Kawamoto S, Tago M, Kawahara N, Morita A, Ueki K, Kirino T (2001) Analysis of treatment outcome after stereotactic radiosurgery for cavernous sinus meningiomas. J Neurosurg 95: 435-439 doi:10.3171/jns.2001.95.3.0435

20. Shinya $Y$, Hasegawa H, Shin M, Sugiyama T, Kawashima M, Takahashi W, Iwasaki S, Kashio A, Nakatomi H, Saito N (2019) Long-Term Outcomes of Stereotactic Radiosurgery for Vestibular Schwannoma Associated with Neurofibromatosis Type 2 in Comparison to Sporadic Schwannoma. Cancers (Basel) 11 doi:10.3390/cancers11101498

21. Nagano O, Higuchi Y, Serizawa T, Ono J, Matsuda S, Yamakami I, Saeki N (2008) Transient expansion of vestibular schwannoma following stereotactic radiosurgery. J Neurosurg 109: 811-816 doi:10.3171/JNS/2008/109/11/0811

Page $11 / 15$ 
22. Mindermann T, Schlegel I (2014) How to distinguish tumor growth from transient expansion of vestibular schwannomas following Gamma Knife radiosurgery. Acta Neurochir (Wien) 156: 1121-1123 doi:10.1007/s00701-0142063-3

23. Kano H, Niranjan A, Kondziolka D, Flickinger JC, Dade Lunsford L (2009) Stereotactic radiosurgery for trigeminal schwannoma: tumor control and functional preservation Clinical article. J Neurosurg 110: 553-558 doi:10.3171/2008.7.jns0812

24. Albano L, Losa M, Nadin F, Barzaghi LR, Parisi V, Del Vecchio A, Bolognesi A, Mortini P (2019) Safety and efficacy of multisession gamma knife radiosurgery for residual or recurrent pituitary adenomas. Endocrine 64: 639-647 doi:10.1007/s12020-019-01876-2

25. Lee WJ, Cho KR, Choi JW, Kong DS, Seol HJ, Nam DH, Lee JI (2020) Gamma knife radiosurgery as a primary treatment for nonfunctioning pituitary adenoma invading the cavernous sinus. Stereotact Funct Neurosurg 98: 371-377 doi:10.1159/000508737

26. Yu J, Li Y, Quan T, Li X, Peng C, Zeng J, Liang S, Huang M, He Y, Deng Y (2020) Initial gamma knife radiosurgery for nonfunctioning pituitary adenomas: results from a 26-year experience. Endocrine 68: 399-410 doi:10.1007/s12020020-02260-1

27. Lee CC, Sheehan JP, Kano H, Akpinar B, Martinez-Alvarez R, Martinez-Moreno N, Guo WY, Lunsford LD, Liu KD (2017) Gamma knife radiosurgery for hemangioma of the cavernous sinus. J Neurosurg 126: 1498-1505 doi:10.3171/2016.4.JNS152097

28. Wang Y, Li P, Zhang XJ, Xu YY, Wang W (2016) Gamma knife surgery for cavernous sinus hemanginoma: A report of 32 cases. World Neurosurg 94: 18-25 doi:10.1016/j.wneu.2016.06.094

29. Huang CW, Tu HT, Chuang CY, Chang CS, Chou HH, Lee MT, Huang CF (2018) Gamma Knife radiosurgery for large vestibular schwannomas greater than $3 \mathrm{~cm}$ in diameter. J Neurosurg 128: 1380-1387 doi:10.3171/2016.12.JNS161530

30. Nicolato A, Foroni R, Alessandrini F, Bricolo A, Gerosa M (2002) Radiosurgical treatment of cavernous sinus meningiomas: experience with 122 treated patients. Neurosurgery 51: 1153-1159; discussion 1159-1161 doi:10.1097/00006123-200211000-00009

31. Maruyama K, Shin M, Kurita H, Kawahara N, Morita A, Kirino T (2004) Proposed treatment strategy for cavernous sinus meningiomas: a prospective study. Neurosurgery 55: 1068-1075 doi:10.1227/01.neu.0000140839.47922.5a

32. Williams BJ, Yen CP, Starke RM, Basina B, Nguyen J, Rainey J, Sherman JH, Schlesinger D, Sheehan JP (2011) Gamma Knife surgery for parasellar meningiomas: long-term results including complications, predictive factors, and progression-free survival. J Neurosurg 114: 1571-1577 doi:10.3171/2011.1.JNS091939

33. Zeiler FA, McDonald PJ, Kaufmann AM, Fewer D, Butler J, Schroeder G, West M (2012) Gamma Knife radiosurgery of cavernous sinus meningiomas: an institutional review. Can J Neurol Sci 39: 757-762 doi:10.1017/s0317167100015572

34. Pollock BE, Stafford SL, Link MJ, Garces YI, Foote RL (2013) Single-fraction radiosurgery of benign cavernous sinus meningiomas. J Neurosurg 119: 675-682 doi:10.3171/2013.5.JNS13206

35. Fariselli L, Biroli A, Signorelli A, Broggi M, Marchetti M, Biroli F (2016) The cavernous sinus meningiomas' dilemma: Surgery or stereotactic radiosurgery? Rep Pract Oncol Radiother 21: 379-385 doi:10.1016/j.rpor.2015.05.002 
36. Leroy HA, Tuleasca C, Reyns N, Levivier M (2018) Radiosurgery and fractionated radiotherapy for cavernous sinus meningioma: a systematic review and meta-analysis. Acta Neurochirurgica 160: 2367-2378 doi:10.1007/s00701018-3711-9

37. Park KJ, Kano H, lyer A, Liu X, Tonetti DA, Lehocky C, Faramand A, Niranjan A, Flickinger JC, Kondziolka D, Lunsford LD (2018) Gamma Knife stereotactic radiosurgery for cavernous sinus meningioma: long-term follow-up in 200 patients. J Neurosurg: 1-10 doi:10.3171/2018.2.JNS172361

38. Hung YC, Lee CC, Guo WY, Shiau CY, Chang YC, Pan DH, Sheehan JP, Chung WY (2019) Gamma knife radiosurgery for the treatment of cavernous sinus meningiomas: post-treatment long-term clinical outcomes, complications, and volume changes. J Neurooncol 143: 261-270 doi:10.1007/s11060-019-03090-6

39. Hafez RF, Morgan MS, Fahmy OM (2015) Stereotactic gamma knife surgery safety and efficacy in the management of symptomatic benign confined cavernous sinus meningioma. Acta Neurochir (Wien) 157: 1559-1564 doi:10.1007/s00701-015-2509-2

40. Kano H, Park KJ, Kondziolka D, lyer A, Liu X, Tonetti D, Flickinger JC, Lunsford LD (2013) Does prior microsurgery improve or worsen the outcomes of stereotactic radiosurgery for cavernous sinus meningiomas? Neurosurgery 73: 401410 doi:10.1227/01.neu.0000431471.64289.3d

41. Sun S, Liu A, Zhang Y (2019) Long-term follow-up studies of gamma knife radiosurgery for postsurgical nonfunctioning pituitary adenomas. World Neurosurg doi:10.1016/j.wneu.2019.01.009

42. Wang X, Zhu H, Knisely J, Mei G, Liu X, Dai J, Mao Y, Pan L, Qin Z, Wang E (2018) Hypofractionated stereotactic radiosurgery: a new treatment strategy for giant cavernous sinus hemangiomas. J Neurosurg 128: 60-67 doi:10.3171/2016.10.JNS16693

43. Sughrue ME, Rutkowski MJ, Aranda D, Barani IJ, McDermott MW, Parsa AT (2010) Factors affecting outcome following treatment of patients with cavernous sinus meningiomas. J Neurosurg 113: 1087-1092 doi:10.3171/2010.3.JNS091807

44. Graffeo CS, Link MJ, Stafford SL, Parney IF, Foote RL, Pollock BE (2019) Risk of internal carotid artery stenosis or occlusion after single-fraction radiosurgery for benign parasellar tumors. J Neurosurg: 1-8 doi:10.3171/2019.8.JNS191285

45. Pikis S, Bunevicius A, Sheehan J (2021) Internal carotid artery stenosis and risk of cerebrovascular ischemia following stereotactic radiosurgery for recurrent or residual pituitary adenomas. Pituitary 24: 574-581 doi:10.1007/s11102-021-01134-7

\section{Figures}


A

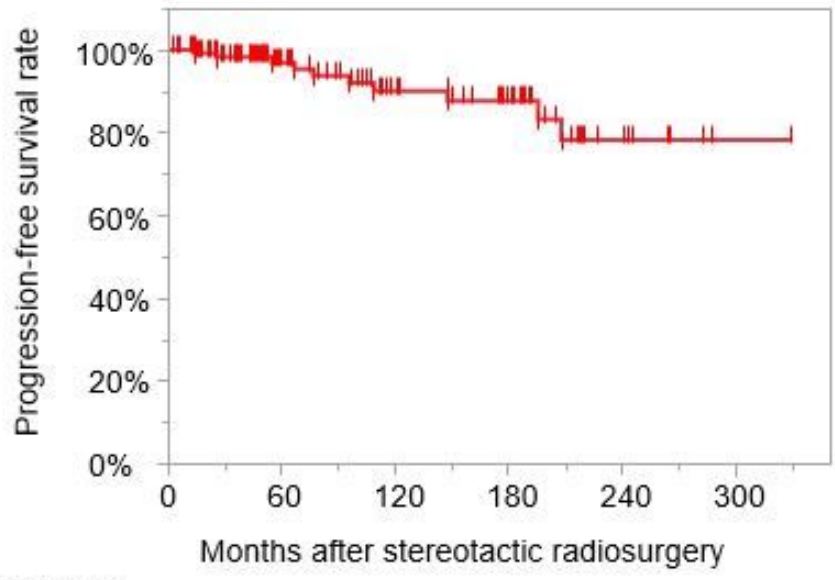

Number at risk

All tumors

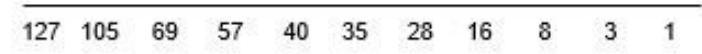

B

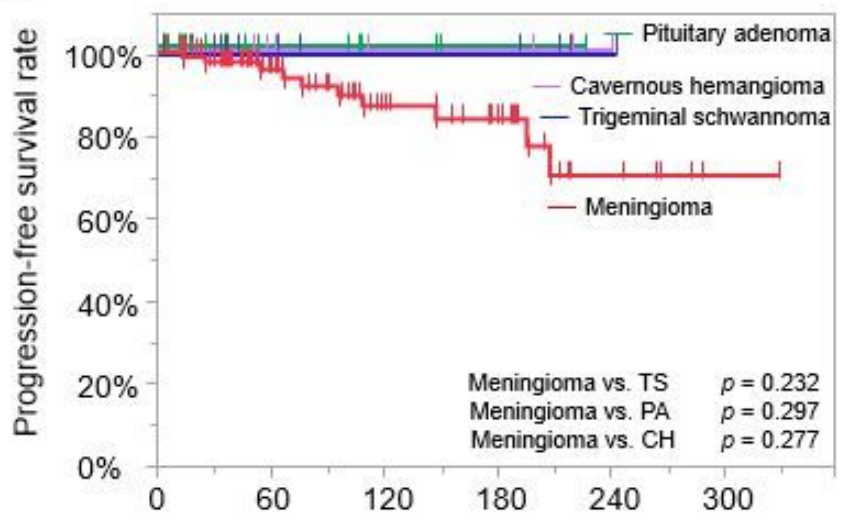

Number at risk

$\begin{array}{llllllllllll}\text { Meningioma } & 91 & 79 & 52 & 43 & 30 & 26 & 20 & 10 & 6 & 3 & 1\end{array}$

$\begin{array}{llllllllll}\text { Trigeminal schwannoma } & 14 & 11 & 6 & 4 & 4 & 4 & 4 & 3 & 1\end{array}$

$\begin{array}{lllllllll}\text { Pituitary adenoma } & 14 & 8 & 6 & 6 & 3 & 2 & 1 & 1\end{array}$

$\begin{array}{llllllllll}\text { Cavernous hemangioma } & 8 & 7 & 5 & 4 & 3 & 3 & 3 & 2 & 1\end{array}$

C

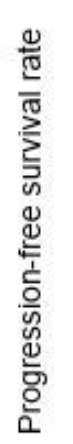

Number at risk

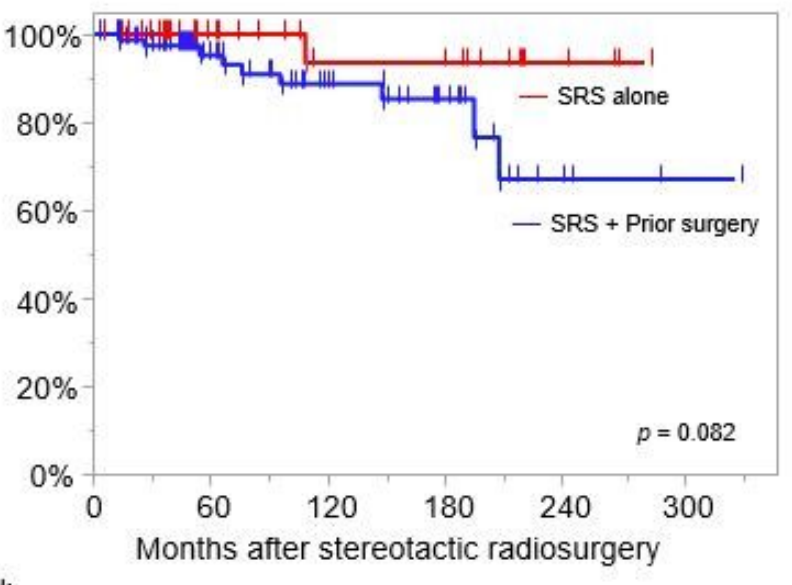

SRS alone

$\begin{array}{llllllllll}38 & 33 & 22 & 18 & 13 & 13 & 13 & 9 & 4 & 1\end{array}$

D

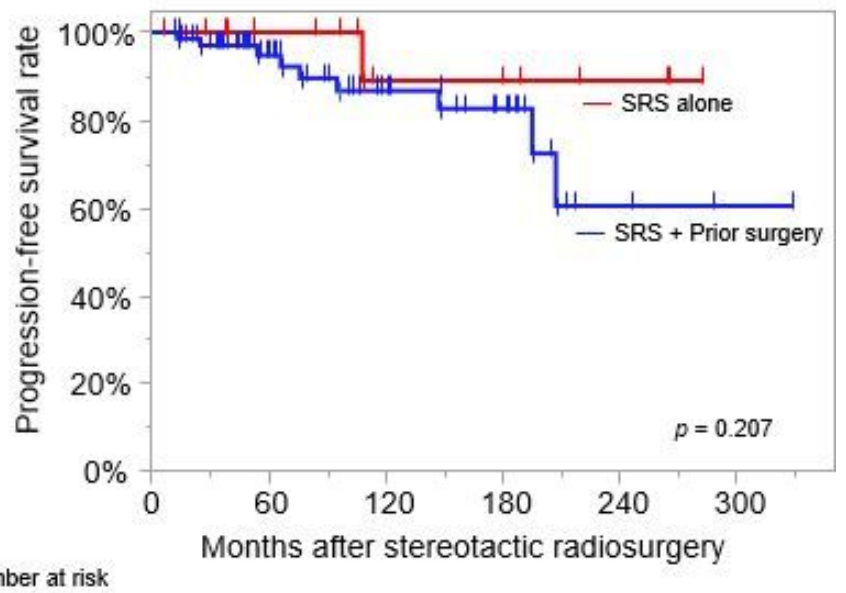

Number at risk

$\begin{array}{lllllllllll}\text { SRS alone } & 19 & 17 & 12 & 11 & 7 & 7 & 7 & 5 & 3 & 1\end{array}$

$\begin{array}{llllllllllll}\text { SRS with prior surgery } & 72 & 62 & 40 & 32 & 23 & 19 & 13 & 5 & 3 & 2 & 1\end{array}$

\section{Figure 1}

Kaplan-Meier curves for (A) progression-free survival rates for the entire cohort, (B) progression-free survival rates comparing meningiomas, trigeminal schwannomas (TS), pituitary adenomas (PA), and cavernous hemangiomas (CH), (C) progression-free survival rates comparing SRS alone and SRS with prior surgery, and (D) progression-free survival rates in meningioma comparing SRS alone and SRS with prior surgery. 
A

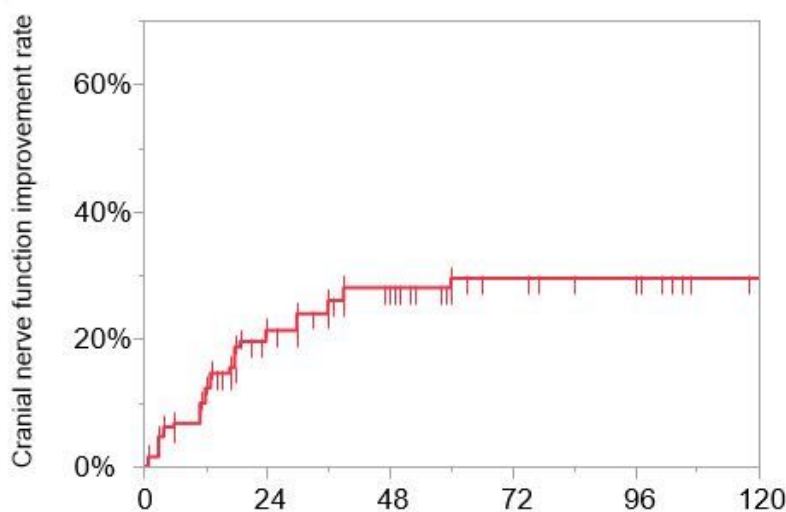

Number at risk

All tumors
Months after stereotactic radiosurgery

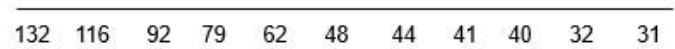

B

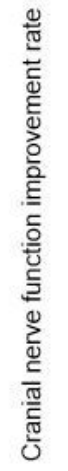

Number at risk

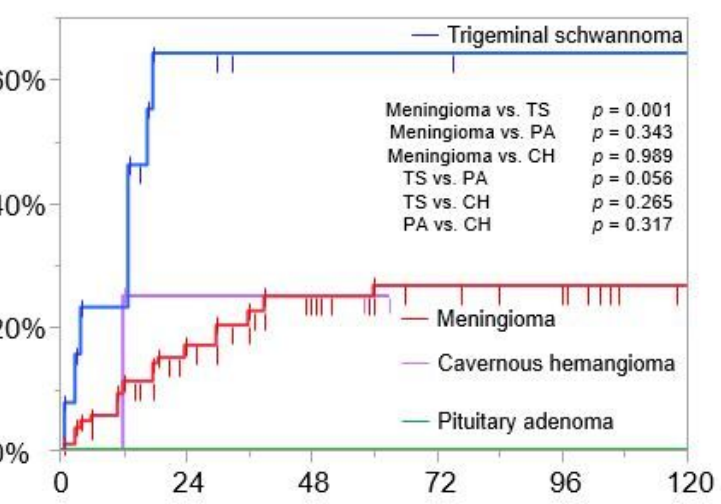

Months after stereotactic radiosurgery

$\begin{array}{lccccccccccc}\text { Meningioma } & 111 & 98 & 82 & 72 & 55 & 44 & 41 & 39 & 38 & 30 & 29 \\ \text { Trigeminal schwannoma } & 13 & 10 & 4 & 2 & 2 & 2 & 2 & 1 & 1 & 1 & 1 \\ \text { Pituitary adenoma } & 4 & 4 & 3 & 2 & 2 & 1 & 1 & 1 & 1 & 1 & 1 \\ \text { Cavernous hemangioma } & 4 & 4 & 3 & 3 & 3 & 1 & & & & & \end{array}$

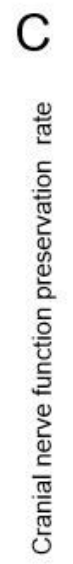

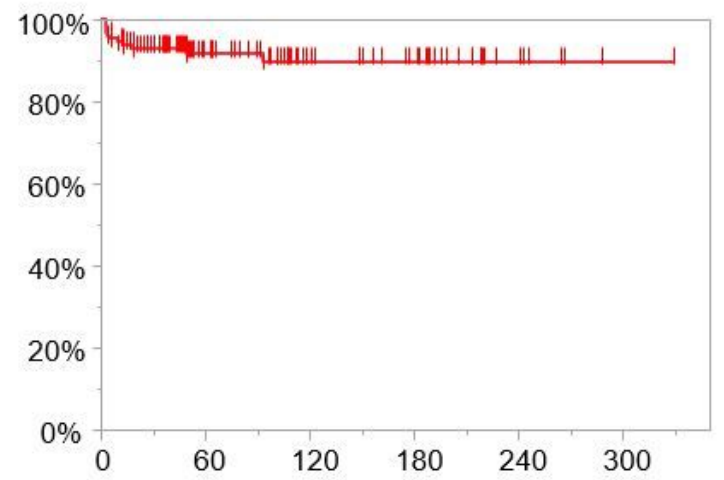

Number at risk

All tumors
D

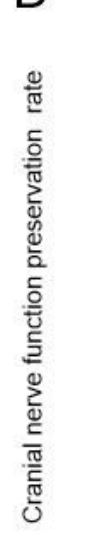

Number at risk Months after stereotactic radiosurgery

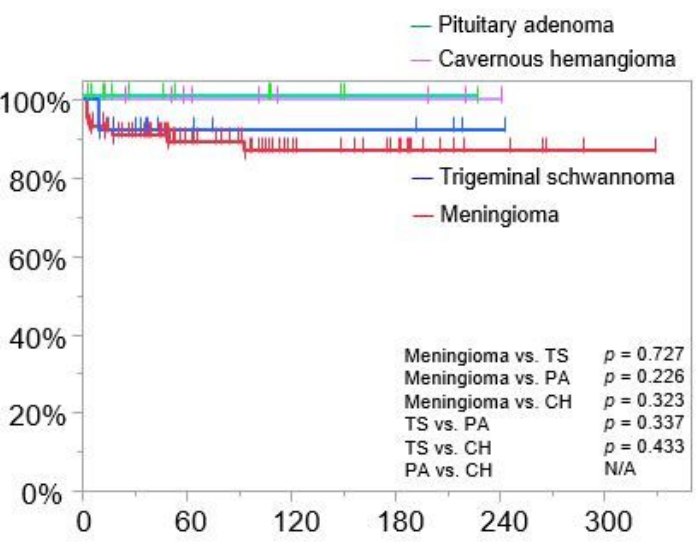

\begin{tabular}{lccccccccccc}
\cline { 2 - 7 } Meningioma & 91 & 72 & 45 & 38 & 24 & 20 & 15 & 8 & 5 & 2 & 1 \\
Trigeminal schwannoma & 14 & 11 & 6 & 4 & 4 & 4 & 4 & 3 & 1 & & \\
Pituitary adenoma & 14 & 8 & 6 & 6 & 3 & 2 & 1 & 1 & & \\
Cavernous hemangioma & 8 & 7 & 5 & 4 & 3 & 3 & 3 & 2 & 1 & &
\end{tabular}

\section{Figure 2}

Kaplan-Meier curves for cranial nerve function improvement rates after radiosurgery in all tumors $(A)$ and improvement rates comparing meningiomas, trigeminal schwannomas (TS), pituitary adenomas (PA), and cavernous hemangiomas (CH) (B). Kaplan-Meier curves of cranial nerve function deterioration rates after radiosurgery in all tumors (C) and deterioration rates comparing meningiomas, trigeminal schwannomas (TS), pituitary adenomas (PA), and cavernous hemangiomas $(\mathrm{CH})(\mathrm{D})$.

\section{Supplementary Files}

This is a list of supplementary files associated with this preprint. Click to download.

- SuppTable.docx 